EDUCATION AND DEBATE

\title{
Researching medicine in context: the Arts and Humanities Medical Scholars Program
}

\author{
E Meites, S Bein, A Shafer
}

J Med Ethics; Medical Humanities 2003;29:104-108

In 2000, the Arts and Humanities Medical Scholars Program at Stanford University School of Medicine issued its first grants to medical students interested in researching an area of the medical arts or humanities in depth. To date, 34 projects have been funded, including renewals. The projects encompass a range of genres and topics, from a website on Asian American health and culture to an ethnographic study of women physicians in training in Spain. Two projects are highlighted here: an online history of medicine course and a poetry project. Students are mentored by faculty from a wide array of university departments and centres and submit completion documents to the committee overseeing the programme. Students are encouraged to present their work at conferences, such as the programme's annual symposium, as well as in publication or other appropriate formats. Future directions include integration with the scholarly concentrations initiative at the medical school.

See end of article for authors' affiliations

Correspondence to: Audrey Shafer, MD, Anesthesia 112A VAPAHCS, 3801 Miranda Ave, Palo Alto, CA 94304, USA; ashafer@ stanford.edu

Accepted

18 September 2003 nvolvement in the scientific process is an intensive experience, and a highly creative one, albeit stylised to test hypotheses using reproducible methods. Research experience during medical education provides training for physician-scientists, ${ }^{1}$ stimulates self learning, ${ }^{2}$ improves faculty research production, ${ }^{3}$ enhances skills such as reading research literature, ${ }^{4-6}$ and promotes interest in fields providing research opportunities. ${ }^{7}$ Indeed, in an attempt to counteract the decreasing numbers of physician investigators in the United States, research programmes have been widely promoted..$^{8-10}$

In 1980, Stanford University School of Medicine, long known as a research centred institution, initiated a Medical Scholars Program to encourage and enable Stanford medical student participation in the creation of new scientific knowledge. ${ }^{11}$ This programme, which provides grant and academic credit for students to perform hypothesis driven projects in bench and clinical research, is taken advantage of by the majority of Stanford students.

In 2000, a new branch of the Medical Scholars Program, the Arts and Humanities Medical Scholars (AHMS) Program, was launched. Modelled on the intensive hands on research experience of the existing Medical Scholars Program, the establishment of the AHMS was driven by the desire to widen opportunities for medical students to engage in medicine in context, that is, medicine in broader frameworks such as the historical, the philosophical, and the cultural. This paper describes the first three years of that programme as well as briefly describing two student projects.

\section{THE AHMS PROGRAM}

Inception and organisation

In 1999, after networking with members of the School of Humanities and Sciences, three faculty physicians with interests in medical humanities submitted a proposal to the medical school to include arts and humanities in a planned expansion of the existing Medical Scholars Program. The successful proposal included: theoretical background to the AHMS programme; the rationale for its development, such as the need for students not only to recognise the human basis of medicine, but also critically to evaluate the culture of medicine using tools gleaned from various disciplines such as history, art, and literature; and the argument that the programme would provide an environment enabling better understanding of the "contextual implications of illness and therapeutic interventions for the individual patient" and society at large. Much of the proposal's theoretical background and programmatic structure were incorporated into the website's overview page. ${ }^{12}$

In January 2000 the first of a series of ongoing planning committee meetings took place. The committee comprises one medical student and eleven faculty members. Six faculty members are from various departments and centres of the medical school (anaesthesia, biomedical ethics, medicine, ophthalmology, psychiatry) and five are university affiliated (Asian languages and comparative literature, Cantor Center for the Visual Arts, history, human biology, music).

Proposal submission process, evaluation, and funding

Proposals are evaluated on five criteria: clarity of proposal, relationship of the project to the arts/ humanities and medicine, feasibility, originality, and educational value to the student. The $\$ 12,000$ grant received by successful applicants to the AHMS programme is substantial, and accompanies 18 units of academic credit. The student can elect to perform the project in the space of one quarter, or to divide the time, money, and credit among multiple quarters. In the case of a project with an ambitious scope-for example, a book, the student must identify which part of the project will be accomplished during the grant interval. Even with projects of narrower 
scope, the grant is frequently seed money, as many students continue work on their project well beyond funded periods. In addition, the student can request travel funds if the project necessitates travel for completion. For detailed information about submission, evaluation, and funding see our website. ${ }^{13}$ This provides information on application procedures, deadlines, and evaluation process; committee members; approved student projects, as well as relevant events, web links, courses; and degree programmes. Forms for the application cover sheet and completion documents can be accessed; future plans include online application.

\section{Student projects and outcomes}

As of the middle of 2003, 34 projects have been approved and funded, including six renewal requests. One funded project was submitted by a group of three students-each was given a full award. The projects are diverse, both in genre and topic. Project genres include: film; writing (scholarly academic, fiction, poetry, journalism, and other non-fiction); website design; visual arts (illustration, cartoon, photography), and curriculum development. Subject matter includes: consciousness and the mind, physician activism, effects of learning anatomy, community clinic artwork, narratives of Delhi women in medicine, empathy, immunology education for children, Haitian Vodun healers, and Native American health beliefs.

Examples of departments and programmes providing faculty mentorship are: anaesthesia, biomedical ethics, Cantor Arts Center, Dean's office, education, English, family and community medicine, history, medicine, music, paediatrics, philosophy, psychology, radiation oncology, and surgery.

\section{DISSEMINATING AHMS RESEARCH RESULTS}

The AHMS Program sponsors an annual spring event, entitled Medicine and the Muse: An Arts, Humanities, and Medicine Symposium, at the Cantor Center for Visual Arts. This evening event, which is organised by a student committee, showcases not only AHMS projects, but also features a keynote speaker, and music, art, and literature by medical students. Apart from this symposium, students have also presented their work at local, national, and international meetings. For example, Shafer A, Meites E, Moffett S. ${ }^{14}$

Project outcomes also include publications, online resources, and curriculum development. For examples of publication see the box below.

\section{TWO STUDENT PROJECTS: A CLOSER LOOK}

The following accounts of successfully completed AHMS projects are described by the students who undertook them. Further information on these and other student projects is available at the AHMS website.

\section{Rewriting medical history by Elissa Meites}

During my first year in medical school, I told our medical history professor I was interested in learning more about the women and people of colour who had contributed to the development of our profession, and he challenged me to research the subject. My curiosity was piqued, and I checked out a few books from the library, intending to present my findings to my professor for possible incorporation into his course.

At the same time I heard about Stanford's new arts and humanities medical scholars programme from a friend, and wondered if I might shape my presentation into a more substantive research project. With these parameters in mind, I wrote a proposal to develop my own class as an alternative to the traditional lecture elective, and I suggested using my computer skills to create a self sustaining online resource.

\section{Examples of publication}

- Book, anthology: Takakuwa K, Rubashkin N, Herzig K, eds. What I learned in medical school: personal stories of young doctors Berkeley, CA: Univ. of California Press. 2004.

- Book, single author: Moffett S. Mind/Matter: A Biography of the Brain Chapel Hill, NC: Algonquin Books. In preparation.

- Scholarly paper: Bhuvaneswar C, Shafer A. Survivor of that time, that place: clinical uses of violence survivors' narratives. J Med Hum. In press.

- Poetry: Bein S. Dreaming Vietnam. JAMA 2003; 289: 1080 also, see below.

- Essay: Hope M. Pain and forgetting. MSJAMA 2003;289:617.

- Illustration: Wong P. Illustrations of craniofacial procedures and anatomy in Plastic Surgery. In press. Her work was highlighted in a news article: Hammerstrom G. Medical scholars programme unleashes the artist within. Stanford Medicine $2001 ; 18: 41$. http://mednews.stanford.edu/ stanmed/2001fall/medicalscholars.html (accessed 29 Sept 2003).

Other projects are web based. These outcomes include:

- Children's book: Park I. Katie has diabetes. Illustrations and animation by Ecker P. 2002 http://www.diabetic. com/children/book.htm (accessed 29 Sept 2003).

- Website: Minor M. Understanding prisoner health care http: //movementbuilding.org/prisonhealth/ (accessed 29 Sept 2003).

- Online course: Meites E. HIPPOCRATES: online history of medicine course, see below).

Curriculum centred projects are also funded. Outcomes include:

- Arts curriculum: Bronson E. Looking with care. Observational skill development using art. Incorporated with work by Dolev J into a required medical school course, http://news-service.stanford.edu/news/2003/february 19/artmed.html (accessed 29 Sept 2003).

Rather than focusing strictly on women in medicine, I proposed to create an inclusive course that integrated diverse contributions to the field with traditional material. I was delighted when I received a grant to work on this project, and set to work.

My first task was to gather materials. I upgraded my computer, readied my digital camera, and purchased web page writing software and image editing programs. I collected texts, images, photographs, sound clips, and hypertext links, finding that the subject of medical history lent itself easily to a multimedia online format.

I also interviewed professors and videotaped lectures about the history of medicine on campus. Materials were abundant, and I had to sort through a vast array of sources to find those I felt were most appropriate for a useful and entertaining medical student resource.

My references included texts on medical history and the history of women in science, as well as ethics, public health, anthropology, and art history. From these, I made deliberate attempts to extract histories of healers from 
differing socio-economic strata, as well as descriptions of classically famous physicians and cases. These efforts extended to my selection of media as well, as I sought out pictures and sound clips that included people of varying genders, colours, and classes.

The enormous scope of my project led to a quick reality check: I had to set some limits on my vision, or I would never be able to complete it. I decided to focus on creating a fully online course that students could complete for one unit of elective credit. Setting this concrete and achievable goal certainly motivated my work to complete the project.

I also faced a challenge in framing the entire history of Western medicine in an easily navigable format. I settled on a structure of eight chapters, each based on a distinct geohistorical period: ancient medicine; Egypt and Babylonia; Greek medicine; Roman medicine; European medicine in the Middle Ages; Renaissance medicine; 18th century schools of thought, and technological medicine. I still, however needed a consistent framework within each chapter. For this I turned to another discipline, anthropology, and the five "core clinical functions" described by Arthur Kleinman, ${ }^{15}$ to analyse medical systems across cultures separated by geographical boundaries. I suspected these functions might also help compare healing systems from differing historical cultures as well.

I created a consistent navigation bar to allow students to peruse sections based on each of Kleinman's clinical functions in every chapter. These included: the illness experience; seeking care; particular conditions; healing activities; and therapeutic outcomes, to which I also added an introductory section on historical background, and a closing section on influence on modern practices.

A final challenge was, of course, finding time to work on my project. Key developments might have to be postponed for final exams or patient interviews. I tended to get the most work done early in the academic quarter or on holidays from classes and clinics.

To make the course fully sustainable online, I created a computer graded quiz for the end of each chapter. Students completing all eight quizzes online would receive one unit of academic credit for the course. Because students would have ready access to the informational content of the course as they completed the quizzes, I decided to ask contextual rather than fact based questions, requiring students to place themselves within a particular historical context to answer the question. Multiple choice answers might all be historically correct, though anachronistic in the context of the chapter. One example from the chapter on Greek medicine follows.

It is winter, and your cousin has been coughing incessantly, often producing a brownish mucous. He has also been withdrawn and is not speaking with any of his usual companions. He sometimes puts his hand on his chest and says breathing pains him. After attending a lecture by Empedocles, you realise:

a. Your cousin has tuberculosis and must be treated with antibiotics.

b. He has an imbalance of phlegmatic humour, and must keep warm and dry to counteract its watery effect.

c. A shaman has placed a curse on your cousin; he should apologise to a friend he recently offended.

d. Your cousin should be quarantined at an Adirondack mountain resort for six months of bed rest.

e. Because the spotted leaves of the lungwort plant resemble a diseased lung, it can be used to cure your cousin's chest ailment.

By the end of my third year in medical school, I had received official approval from our Committee on Courses and Curriculum, and proudly unveiled a new online course at Stanford Medical School, which offered an accessible, fun, and gender balanced retelling of the history of Western medicine (see course preview on the website). ${ }^{16}$

As a key component of any research project is a good acronym, I dubbed my course HIPPOCRATES: the History of Physicians and Patients Online-Creative Resources for Ancient Time Exploration at Stanford.

I have been overwhelmed with the positive response to this course, both from colleagues at my own medical school and from others around the world, and have enjoyed discussing this project at national and international conferences. I believe my experience with interdisciplinary scholarship has strengthened my personal emphasis on patient centred clinical care, and I also feel confidently equipped to pursue my professional academic goals.

Though I believe any study of the history of medicine to be useful for people involved in the medical field, my hope is that the anthropological perspective of my course will also emphasise that even the medical decisions we consider objective today do occur in a historical and cultural context. In addition, I hope my diverse classmates will see a bit of themselves in the men and women who shaped our field, and be inspired to pursue their own places in the history of medicine.

Inventing narrative and cause in illness by Sarah Bein Having been a writer for some years, writing mostly poetry, I decided to channel my interest in the subjective landscape of the patient by depicting their plight through poetry. My project, entitled The Poetry of Healing: Inventing Narrative and Cause in Illness, consists of a manuscript of poems written from the perspective of both the patient and the physician, as well as a short prose poem from the perspective of one patient, written from her hospital bed as she reviews the experiences that have shaped her life.

Literature provides its reader with a passport into the emotional experience of its writer. By writing from the perspective of both patient and caregiver, my aim is to enable the reader access to both worlds, thus collapsing the boundaries between patient and physician. The backbone of my arts and humanities medical scholars project consists of several questions, namely, how do physicians perceive the ill; how do patients perceive their illness and the doctors who care for them, and more importantly, how does "being sick" alter one's own emotional landscape and consciousness. In attempting to answer these questions, I found that too often the emotional wellbeing of the patient is lost beneath medical formalities and jargon, and that the objectivity of a disease label is most often preferred to the subjective experience of the individual suffering with his or her own discrete illness.

An example of a poem from my collection is in the box below, entitled 'Bone Story'.

In the poem, the narrator equates the course of an illness with the course of nature and the month of August, which returns her to that place of memory and reflection which disease inspires. Just as nature's prowess is taken for granted and expected, so is the health of the body. In this way, the lines "Remembering bruises where veins run/rivers over rocky bones" symbolize the invasion of illness into the body.

The narrator expresses her desire for metamorphosis and change from sickness into health, via her identification and personification of the sea gull who "Invent[s] sea squid and star fish in tangled green masses" just as the gull morphs kelp into sea animals, so is the narrator's desire to change her body back to health, where she feels and felt, "safe." The last line of the poem reiterates the narrator's identification with nature, as she searches for her own safety while dealing with all the uncertainty and fear of illness. 


\section{Bone story}

Why is August the wayward humming of my heart? Mother by the monitor counting-

The dead with their own hearts silent as the breaking day, its peregrines flying off.

At water's edge, a gull tears kelp from another's mouth,

Inventing sea squid and starfish in tangled green masses and I, thinking, Who says you can't take it with you? The salt at the end of the day.

Today I have enough strength to make it down the stairs so I warm the bread the olives the pissaladiere

Remembering bruises where veins run rivers over rocky bones,

Where the fish are safe.

Sarah Bein

This project was intended for publication and for the medical community as a whole in order to help illuminate the plight of patients to their physicians and to acknowledge that patients are not alone in their struggle. Many poems have already been accepted for publication in both medical and literary journals, such as JAMA, Red River Review, and Offerings. This project has helped strengthen my desire to work with chronically ill children and to continue my interest in doctorpatient communication.

\section{CHALLENGES AND FUTURE DIRECTIONS}

The development of the AHMS Program can be viewed as a branch or bud from a main, established medical student research programme. This model has both advantages and disadvantages. Some structures, resources, and functions in place for the main programme were extended to the branch. Funds for student grants-for example, are garnered from the same source, largely alumni donations. In addition, the Office of Student Affairs employs a medical student part time as webmaster-this student's duties were expanded to include constructing a site for the AHMS Program. The close ties between the AHMS Program and the administration facilitate advertisement of the programme to students and prospective students. Indeed, the admissions committee has been very supportive of the AHMS Program. It is an important ally in the attempt to continue the matriculation of students with diverse interests.

Other programmatic needs, however, had to be negotiated-for example, a part time coordinator salary, or outside funding sought. Some aspects of scholarly work differ so dramatically between the sciences and the humanities, that the branch model has significant drawbacks. For instance, most students wishing to perform bench research find an appropriate laboratory-complete with supplies, protocols, graduate and postdoctoral researchers, etc-and the student joins the team effort. Students in the AHMS Program, however, tend to pursue far more individual projects. Finding appropriate mentors and other resources for these students is sometimes difficult, and the Medical
Scholars Program does not allow for mentorship stipends or other funds beyond the student grant or certain travel funds. Nevertheless, the advantages of the branch model in terms of programmatic support and sustainability are tremendouswithout these the programme would not exist.

Curriculum reform plans at the medical school include the development of scholarly concentrations-areas of study which encompass in-depth, coordinated experiences for students. Each scholarly concentration offers coursework, advising, mentoring and opportunities for scholarly work. Students will be encouraged to spend a year equivalent of time in a research endeavour, and the AHMS Program will be folded into the scholarly concentrations initiative.

\section{SUMMARY}

Traditional medical education opens many doors for medical students. Manoeuvring through an intricate, hierarchical structure, students encounter such doors as: knowledge (of disease, health, and therapeutics); responsibility (for the health care of patients), and privilege (access to relative material comfort and social power compared to much of the world's populace).

Yet, concurrent with the door opening of medical education, other doors are slammed shut. By virtue of the sheer volume of information expected to be absorbed, the competitive nature of applying for postgraduate opportunities, and the hours required for fulfilment of course and clinical attachment (clerkship) responsibilities, many students quickly learn to shed prior interests and activities, and have few incentives to develop new ones.

In order to survive the demands of medical school, students focus on goals of codified achievement, such as medical board scores and honours (or honours equivalent) grades. As well as conforming to the enormous social influences of hospital mores and performance pressures, ${ }^{17} 1819$ students often narrow their interests to those deemed paramount to achieving success in the biotech world of modern medicine and medical education.

It could be argued, however, that the technological and scientific emphasis of most undergraduate medical education programmes only partially prepares young doctors for the task ahead of them. The practice of medicine remains a human endeavour, centred on personal encounters and filled with all the complexities and nuances that such interactions encompass.

The interdisciplinary field of medical humanities seeks to complement traditional medical education by addressing these complexities, and, indeed, celebrating them. In general, however, intensive experiences in developing creativity skills (as opposed to "finding the answer", also known as convergent thinking skills), ${ }^{20}$ are absent from traditional medical education.

The AHMS Program provides medical students with a chance to enlarge their understanding and experience of medicine while honing valuable, translatable skills, such as writing a fundable proposal, garnering mentorship, finding creative solutions to unforeseen problems, and completing and presenting a project. The arts and humanities facilitate both a broader and more critical view of medicine in the context of society's cultures, histories, and vagaries. An opportunity for medical students to intensively explore an intersection between the arts, humanities, and medicine can open the doors of creativity, innovation, and reflection which otherwise can feel so oppressively closed during medical education.

\section{Authors' affiliations \\ E Meites, S Bein, Stanford University School of Medicine, Stanford, California, USA}


A Shafer, Department of Anesthesia, Stanford University School of Medicine, and Anesthesia Service, Veterans Affairs Palo Alto Health Care System, Palo Alto, California, USA

Student support from the Stanford Arts and Humanities Medical Scholars Program

\section{REFERENCES}

1 Wilkerson L, Abelmann WH. Producing physician-scientists: a survey of graduates from the Harvard-MIT Program in Health Sciences and Technology. Acad Med 1993;68:21 4-18.

2 Fisher WR. Medical student research: a program of self education. J Med Educ 1981;56:904-8.

3 Cursiefen C, Altunbas A. Contributions of medical student research to the Medline indexed publications of a German medical faculty. Med Educ 1998;32:439-40.

4 McPherson JR, Mitchell MM. Experience with providing research opportunities for medical students. J Med Educ 1984;59:865-8.

5 Frishman WH. Student research projects and theses: should they be a requirement for medical school graduation? Heart Dis 2001;3:140-4.

6 Griswold K, Silverstein D, Lenkei E, et al. Research skills for medical students: a summer assistantship in family medicine. Fam Med 1991;23:306-7.

7 Gonzales AO, Westfall J, Barley GE. Promoting medical student involvement in primary care research. Fam Med 1998;30:113-16.
8 Kemph JP, Claybrook JR, Sodeman WA Sr. Summer research program for medical students. J Med Educ 1984;59:708-13.

9 Zier K, Stagnaro-Green A. A multifaceted program to encourage medical students' research. Acad Med 2001;76:743-7.

10 Mark AL, Kelch RP. Clinician scientist training program: a proposal for training medical students in clinical research. J Investig Med 2001;49:486-90.

11 Jacobs CD, Cross PC. The value of medical student research: the experience at Stanford University School of Medicine. Med Educ 1995;29:342-6.

12 Overview page. http://arts-hum-med. stanford.edu (accessed 29 Sept 2003).

13 http://arts-hum-med.stanford.edu (accessed 29 Sept 2003).

14 Shafer A, Meites E, Moffeett S. Branching out. The Stanford Arts and Humanities Medical Scholars Program. Centre for Medical Humanities 3rd Annual Medical Humanities Conference, Healing Partners: Learning from Each Other. London, UK, 20 March 2002.

15 Kleinman A. Patients and healers in the context of culture. Berkeley: University of California Press, 1980.

$16 \mathrm{http}: / /$ www.stanford.edu/group/hippocrates/preface.html (accessed 29 Sept 2003).

17 Wear D. The House of God: another look. Acad Med 2002;77:496-501.

18 Wilkes $M$, Raven $B H$. Understanding social influence in medical education. Acad Med 2002;77:481-8.

19 Anderson KD, Jacobs DM, Blue AV. Is match ethics an oxymoron? Am J Surgery 1999; 177:237-9.

20 Lippell S. Creativity and medical education. Med Educ 2002;36:519-21.

\section{BOOK REVIEW}

\section{Medicine and Art}

Edited by A E H Emery, M L H Emery. Royal Society of Medicine Press, 2003, (hbk), pp 112 $+x$. ISBN 1853155012

Alan and Marcia Emery have compiled a captivating collection of 53 colour plates of health care practitioners and their patients, from the third century $\mathrm{BC}$ to the beginning of the current millennium. Each plate is reproduced to a high standard with a facing page of text. There is also an appendix detailing "a selection of medical conditions depicted in paintings". The editors have been imaginative in their choice of images. Of course, old favourites-like The Doctor (c 1891) by Sir Luke Fildes and The Mission of Mercy: Florence Nightingale Receiving the Wounded at Scutari (1857) by Jerry Barrett—are included. But examples of Eastern art temper the Western dominance, and although most of the illustrations are of paintings, early medicine is represented in sculpture, pottery, and coins.

The textual entries that accompany the plates are of variable length and quality. Some offer an interpretation of the visual effects. So with Sentence of Death (1908) by John Collier we are told that the patient receiving bad news "sits uncomfortably, staring ahead, isolated in his grief. He sees no future. His facial pallor and demeanour contrast starkly with those of the doctor" (p $76)$. On other occasions, there are references to the artistic background. Francisco Oller y Cestero's painting of The Student (c 1860s), for instance, is described as "interesting" because of the influence of both the "French realists" and the "emerging Impressionists" (p 56), and Ernest Board's study of Laënnec Listening to the Chest of a Patient (c 1910) is identified as one of a series of paintings of the same subject. Furthermore, the relationship between art and society is also recognised, though not explored in any depth. Edward Hopper's Drug Store (1927) is thus read as a statement of "the stark loneliness of modern city life ( $\mathrm{p} 86$ ), whilst Sergei Chepik is quoted defining his portrait of The Madhouse (1987) as "an allegorical representation of Soviet society, walled in by its own lies, paranoia and despair" (p 100).

In addition to being seen as sociocultural artefacts, the works are also pretexts for brief asides about the historical development of health care and its contemporary practice. To Louis-Léopold Boilly's painting of a Vaccination (1807) is attached the story of Edward Jenner. High infant mortality rates are mentioned in connection with Doubtful Hope (1875) by Frank Holl, in which an anxious mother with baby is shown waiting for a prescription. And women's belated entry into medicine is celebrated in Children's Doctor (1949) by Andrew Wyeth, a study of Dr Margaret Handy who "graduated from Johns Hopkins in $1916 \ldots$ and was one of the first to specialise in paediatrics" (p 92).

For readers of Medical Humanities, the relevance of art to contemporary health care may be of special interest. Engaging in art is itself a restorative process as Stanley Spencer appreciated when he crafted Bed Making (1932) and the other panels at the Sandham Memorial Chapel, Berkshire. A member of the Royal Army Medical Corps during the first world war (1914-18), he insisted that the murals "redeemed" his experience, enabling him to "recover my lost self" ( $p$ 82). The editors also, however, deduce lessons from their collection. Therefore, the nineteenth century Medical Painting from Central Tibet, which captures the holism of Buddhist practice, is used to highlight the disappointments of "modern scientifically based medicine" (p 6) and to promote the advantages of cooperation between conventional and complementary practitioners. Conversely, Louise Riley's embroidery of The Patient and Researcher (2001) sought "to describe the physical aspect of the removal of organs and blood samples from the patient, and their redirection to a laboratory where a researcher would experiment, attempting to ascertain a diagnosis or cure-putting the puzzle pieces back together". The dehumanisation that such medical research may bring is pointed up, and emphasis given to the "care and compassion" (p 106) expressed in Norman Rockwell Visits a Family Doctor (1947) and his earlier portrait, Doctor and Doll (1929), where the physician wins the confidence of a young patient by listening to her doll's chest.
The ideal that emerges from this critique of modern medicine is essentially a paternalistic one. Pictures of patients are thin on the ground and when they do appear it is often as passive objects of the medical gaze. Therefore, no comment is made about the plight of the patient put on public display in paintings such as Doctor Teaching on a Sick Child Before an Audience of Doctors and Students, New York Polyclinic School of Medicine (1891) by Irving $\mathrm{R}$ Wiles. Health care practitioners other than doctors are also neglected. Their subordination is evident in Science and Charity (1897) by Pablo Picasso where the doctor's "skill and knowledge" (p 72) is exhibited in taking the pulse, whilst the nun's caring role is manifest in attending to the patient's material needs. In The Compassion of the Intensive Care Sister (1989) by Roy Calne, on the other hand, the unobtrusiveness of the medical technology accentuates the responsibilities of the nurse.

The field of medicine and art has recently seen the publication of several scholarly studies, among them Fiona Haslam's From Hogarth to Rowlandson: Medicine in Art in Eighteenth-Century Britain (Liverpool: Liverpool University Press, 1996) and Ludmilla Jordanova's Defining Features: Scientific and Medical Portraits, 1660-2000 (London: Reaktion in association with the National Portrait Gallery, 2000). The contents of the Clement C Fry Collection at the Yale University Medical Library have also been listed by Susan Wheeler in Five Hundred Years of Medicine in Art: An Illustrated Catalogue of Prints and Drawings (Aldershot: Ashgate, 2001), and the visual resources of the National Library of Medicine in the USA are available online (www.ihm.nlm. nih.gov).

Medicine in Art cannot match the range or weight of these projects. In particular, the short introduction of just one page means that the plates lack being placed in a proper context in the history and theory of art, which would acknowledge their ability to form as well as "reflect ... the role of the physician in society" (p ix). Nevertheless, as a popular, accessible introduction, the book is a treasure trove for health care practitioners and the general public alike.

A Borsay a.borsay@swansea.ac.uk 